\title{
THE ROAD TO A CURE
}

\section{Characterization of a New HIV Antibody}

ZACKARY PARK, SEUNG YUB HAN, ALEXANDREA RAMNARINE, JAMES KLEINSCHMIDT, KIMBERLYN AUSTIN, BRENDAN HUSTEAD, MATTHEW SLEIN, CATHERINE PHALEN, ARIANA GONZALEZ

A PHAGE DISPLAY LIBRARY WAS PREVIOUSLY CONSTRUCTED FROM AN SIV-INFECTED RHESUS MACAQUE. SEVERAL SINGLE CHAIN FV (SCFV) WERE SELECTED USING PHAGE DISPLAY TECHNOLOGY. SEQUENCES CORRESPONDING TO SU24, SU343 AND LL25X WERE OPTIMIZED FOR EXPRESSION IN A MAMMALIAN SYSTEM AND COMMERCIALLY SYNTHESIZED. IN THIS STUDY, WE AIMED TO CHARACTERIZE THE SPECIFICITY OF SU24, SU343, AND LL25X. THE CODON-OPTIMIZED VERSION OF THE SCFV LL25X GENE SEQUENCE WAS CLONED INTO A MAMMALIAN EXPRESSION VECTOR (PCEP4). LL25X DNA WAS AMPLIFIED BY PCR, AND THE PCR PRODUCT AND MAMMALIAN EXPRESSION VECTOR WERE BOTH DIGESTED WITH KPNI/SAPI RESTRICTION ENZYMES. THE FRAGMENTS WERE LIGATED USING T4DNA LIGASE. E. COLI CELLS WERE TRANSFORMED WITH THE LIGATION REACTION. SINGLE COLONIES WERE SELECTED ON LB AGAR PLATES CONTAINING THE SELECTIVE ANTIBIOTIC (AMPICILLIN). POSITIVE COLONIES WERE IDENTIFIED WITH KPNI AND SAPI. SANGER SEQUENCING CONFIRMED CLONING RESULTS AND DNA SEQUENCE ACCURACY. FOLLOWING TRANSFECTION OF MAMMALIAN CELLS (293T), LL25X-FC CELLS, AND PURIFYING OUR PROTEIN, THE BINDING OF LL25X-FC TO THE SIV GPI4O ENVELOPE PROTEIN WAS CONFIRMED. 


\section{INTRODUCTION}

Since the discovery of HIV-AIDS in I984, an effective vaccine has remained an elusive goal, despite the conjugation of numerous efforts. Progress made in the RVI44 Thai vaccine trial has hinted that HIV envelope glycoprotein variable loop VI-V2 has a role in the prevention of infection. The isolation of anti-SIV monoclonal antibodies $(\mathrm{mAb})$ will allow a pre-clinical evaluation of such antibodies in the SIV-rhesus macaque model of HIV/AIDS pathogenesis and vaccine.

A phage display library was previously constructed from a SIV-infected rhesus macaque, and several single chain variable fragments ( $\mathrm{scFv}$ ) such as $\mathrm{SU}_{24}, \mathrm{SU}_{343}$, and LL25X were selected using phage display technology. ${ }^{2}$ Sequences corresponding to $\mathrm{SU}_{24}, \mathrm{SU}_{343}$, and LL25X were optimized for expression in a mammalian system and commercially synthesized (IDT DNA). SU24 and SU343 had previously been cloned in a mammalian expression vector. In this study, we aimed to characterize the specificity of $\mathrm{SU}_{24}, \mathrm{SU}_{343}$, and LL25X.

\section{MATERIALS AND METHODS}

\section{PCR( Polymerase Chain Reaction) Amplification}

The codon-optimized version of the LL25X gene was to be amplified by PCR. A PCR mixture was prepared in a PCR tube. The PCR mixture consisted of I $\mu \mathrm{L}$ of template DNA (Ioo ng - I $\mu \mathrm{g}$ ), $2 \mu \mathrm{L}$ of forward primer (FP), $2 \mu \mathrm{L}$ of reverse primer (RP), and $45 \mu \mathrm{L}$ of Platinum PCR Supermix High Fidelity from Thermo Fisher Scientific. The forward primer was LL25-co-F (GGCCGGTACCGGCGCGCCACCATGG) and included the restriction site for KpnI. The reverse primer was LL25-co-R (ATTGTACTGCTCTTCCCGTGGCTTGGTTTTCGC) and included the restriction site for SapI. The PCR tube was closed tightly, mixed via vortex, and spun down using a small bench-top rotor.

The PCR tube was placed in a thermocycler for 25 cycles. The initial denaturation step was performed at $94^{\circ} \mathrm{C}$ for 5 minutes and was followed by 25 cycles of denaturation ( $94^{\circ} \mathrm{C}$ for 30 seconds), annealing $\left(50^{\circ} \mathrm{C}\right.$ for 30 seconds), and extension $\left(68^{\circ} \mathrm{C}\right.$ for I minute). A final extension step was performed at $62^{\circ} \mathrm{C}$ for io minutes.

DNA gel electrophoresis of the PCR products was performed on I\% agarose gel. The DNA vector was observed around I092 bp under a UV transilluminator and was extracted using a gel extraction kit (QIAGEN).

\section{Extraction of PCR Products}

The PCR products were extracted from the I\% agarose gel following the QIAquick Gel Extraction Kit by QIAGEN. Instead of the recommended $50 \mu \mathrm{L}$ of Buffer EB, $30 \mu \mathrm{L}$ of double distilled water was added to the QIAquick membrane column to elute DNA and centrifuged immediately. Loading Dye was not added to purified DNA.

\section{Double Digestion of PCR Products with KpnI and SapI}

After gel extraction, the DNA vector from PCR was double digested with KpnI and SapI. The double digest reaction mixture consisted of $30 \mu \mathrm{L}$ of the DNA vector, $4 \mu \mathrm{L}$ of CutSmart Buffer from New England Biolabs, I $\mu \mathrm{L}$ of KpnI, I $\mu \mathrm{L}$ of SapI, and $4 \mu \mathrm{L}$ of double distilled water for a total concentration of $40 \mu \mathrm{L}$. DNA gel electrophoresis of the double digested LL25X PCR product was performed on I\% agarose gel for I hour.

\section{Extraction of PCR Fragment Double Digested with KpnI and SapI}

The DNA of the insert vector resulting from the PCR fragment double digested with KpnI and SapI was extracted from the I\% agarose gel using the QIAquick Gel Extraction Kit protocol by QIAGEN. Instead of the recommended $50 \mu \mathrm{L}$ of Buffer EB, $30 \mu \mathrm{L}$ of double distilled water was added to the QIAquick membrane column to elute DNA and centrifuged immediately. Loading Dye was not added to purified DNA.

Double Digestion of Mammalian Expression Vector $p C E P_{4}$ with KpnI and SapI

Three samples were prepared for the double digest with $\mathrm{KpnI}$ and SapI was performed on the mammalian expression vector $\mathrm{pCEP}_{4}$. One sample was the reaction mix for the double digest consisted of I $\mu \mathrm{L}$ of cloning vector pCEP $4,2 \mu \mathrm{L}$ of CutSmart Buffer from New England Biolabs, I $\mu \mathrm{L}$ of KpnI, I $\mu \mathrm{L}$ of SapI, and I5 $\mu \mathrm{L}$ of double distilled water. The other two samples served as controls. Control I, the reaction mix for the single digest using KpnI, consisted of I $\mu \mathrm{L}$ of cloning vector pCEP $4,2 \mu \mathrm{L}$ of CutSmart Buffer from New England Biolabs, I $\mu \mathrm{L}$ of KpnI, o $\mu \mathrm{L}$ of SapI, and I6 $\mu \mathrm{L}$ of double distilled water. Control 2 , the reaction mix for the single digest using SapI, consisted of $\mathrm{I} \mu \mathrm{L}$ of cloning vector $\mathrm{pCEP}_{4}, 2 \mu \mathrm{L}$ of CutSmart Buffer from New England Biolabs, $\circ \mu \mathrm{L}$ of KpnI, I $\mu \mathrm{L}$ of 
SapI, and I6 $\mu \mathrm{L}$ of double distilled water. DNA gel electrophoresis was performed on the sample reaction mix and the reaction mixes of the two controls on $\mathrm{I} \%$ agarose gel for I hour.

Extraction of Mammalian Expression Vector $p \mathrm{CEP}_{4}$ Double Digested with KpnI and SapI

The DNA backbone vector of mammalian expression vector pCEP4 double digested with KpnI and SapI was extracted from the I\% agarose gel using the QIAquick Gel Extraction Kit protocol by QIAGEN. Instead of the recommended $50 \mu \mathrm{L}$ of Buffer EB, $30 \mu \mathrm{L}$ of double distilled water was added to the QIAquick membrane column to elute DNA and centrifuged immediately. Loading Dye was not added to purified DNA.

\section{Ligation of LL25X into Backbone Vector pCEP4}

DNA gel electrophoresis of $2 \mu \mathrm{L}$ of the double digested backbone vector $\mathrm{pCEP}_{4}$ and $2 \mu \mathrm{L}$ of the double digested LL25X PCR product was performed on $1 \%$ agarose gel for I hour. Based on the band intensities on the gel, the volumes for the backbone and insert vectors could be estimated to achieve a backbone-to-insert ratio of $\mathrm{I}: 2$ or greater. Two tubes were prepared. One tube was for ligation, and the other tube served as a control. The reaction mixture for ligation of the double digested LL25X PCR product into backbone vector $\mathrm{pCEP}_{4}$ consisted of 2 $\mu \mathrm{L}$ of the backbone vector (KpnI/SapI-digested pCEP4), 4 $\mu \mathrm{L}$ of the insert vector (KpnI/SapI-digested LL25X), $2 \mu \mathrm{L}$ of T3 DNA ligation buffer (Iox), I $\mu \mathrm{L}$ of T4 DNA ligase, and II $\mu \mathrm{L}$ of sterile water. The reaction mixture for the control consisted of $2 \mu \mathrm{L}$ of the backbone vector (KpnI/SapIdigested pCEP4), ○ $\mu \mathrm{L}$ of the insert vector (KpnI/SapIdigested LL25X), $2 \mu \mathrm{L}$ of $\mathrm{T}_{3}$ DNA ligation buffer (IOX), I $\mu \mathrm{L}$ of $\mathrm{T}_{4}$ DNA ligase, and $\mathrm{I} 5 \mu \mathrm{L}$ of sterile water. The ligation reaction products were incubated overnight at room temperature.

\section{Transformation of Ligation Reaction Products into} E. coli TOP1OF

Frozen electrocompetent E. coli TOPioF' was removed from a $-80^{\circ} \mathrm{C}$ freezer and thawed on ice for to minutes. The E. coli was aliquoted to obtain $50 \mu \mathrm{L}$ in a tube, and $7 \mu \mathrm{L}$ of ligation reaction was added to it. The tip of the pipette was swirled in the tube to mix the solution, and the tube was incubated on ice for 30 minutes. The transformation tubes were heat shocked at $42^{\circ} \mathrm{C}$ for I minute and put on ice for 2 minutes. The heat shock allowed the bacterial membranes to be permeable enough for vector $\mathrm{pCEP}_{4}$ containing the LL25X DNA to enter the cells. Afterwards, I $\mathrm{ml}$ of LB media without antibiotics was added to the tube and cultured at $37^{\circ} \mathrm{C}$ for 45 minutes in a shaking incubator at $250 \mathrm{rpm}$. The tube was centrifuged at 9,000 rpm for I minute, and all but too $\mu \mathrm{L}$ of the supernatant was pipetted out. The remaining roo $\mu \mathrm{L}$ of supernatant was mixed with the bacterial pellet using a pipette tip. All of the bacterial mix was plated onto an LB agar plate containing Ampicillin. A background control of cloning vector pCEP4-Fc-HA, digested and ligated without the LL25X insert vector, was also plated on the selective media.

\section{Colony Screening of Positive Clones on Selective Media}

Growth of the bacterial cells transformed with the pCEP4/ LL25X ligation product was observed on the LB agar plate containing Ampicillin. Two colonies were picked up from the LB agar plate containing Ampicillin and were inoculated with $3 \mathrm{ml}$ of LB media containing $50 \mu \mathrm{g} / \mathrm{ml}$ of Ampicillin in a $\mathrm{I} 5 \mathrm{ml}$ culture tube. The tube was cultured overnight at $37^{\circ} \mathrm{C}$ in a shaking incubator at $250 \mathrm{rpm}$. The day after, $2 \mathrm{ml}$ of bacteria was aliquoted into a $2 \mathrm{ml}$ Eppendorf tube and centrifuged at $13,000 \mathrm{rpm}$ at room temperature to pellet down the bacteria. The supernatant was discarded, and the pellet was obtained.

\section{Extracting the $p C E P_{4} / L L 25 X$ DNA from}

the E. coli Cells via Miniprep

The QIAprep Spin Miniprep Kit protocol by QIAGEN was followed to isolate the pCEP4/LL25X DNA from the E. coli cells. The recommended step involving washing the QIAprep spin column with $0.5 \mathrm{ml}$ of Buffer PB was omitted because endA+ strains or other bacterial strains with high nuclease activity or carbohydrate content were not used. None of the optional steps were taken, such as adding LyseBlue reagent to Buffer Pr. The DNA concentration, determined by using Nanodrop, was I20.2 ng/ $\mu \mathrm{L}$.

\section{Determination of a Positive Clone by Restriction Analysis}

One reaction mix contained the DNA template, and one control tube contained the cloning vector $\mathrm{pCEP}_{4}$. The reaction tube consisted of $3 \mu \mathrm{L}$ of mini-prep DNA, $2 \mu \mathrm{L}$ of CutSmart Buffer from New England Biolabs, I $\mu \mathrm{L}$ of KpnI$\mathrm{HF} / \mathrm{SapI}$, I $\mu \mathrm{L}$ of KpnI-HF/BamHI-HF, and I3 $\mu \mathrm{L}$ of sterile water. The control tube consisted of $3 \mu \mathrm{L}$ of cloning vector pCEP4, $2 \mu \mathrm{L}$ of CutSmart Buffer from New England Biolabs, I $\mu \mathrm{L}$ of KpnI-HF/SapI, I $\mu \mathrm{L}$ of KpnI-HF/BamHI-HF, and I3 $\mu \mathrm{L}$ of sterile water. Both tubes had a total volume of 


\section{"The isolation of anti-SIV monoclonal antibodies (mAb) will allow a pre-clinical evaluation of such antibodies in the SIV-rhesus macaque model of HIV/AIDS..."}

$20 \mu \mathrm{L}$. The tubes were incubated at $37^{\circ} \mathrm{C}$ for I hour, and the products of the double digest were analyzed on a $\mathrm{I} \%$ agarose gel.

\section{Preparation of Samples for DNA Sequencing}

After DNA mini-prep, samples were prepared for DNA sequencing. Recommendations for DNA sequencing from Eton Bioscience were followed. For successful DNA sequencing, the reaction mix consisted of $8 \mu \mathrm{L}$ of the LL25X PCR product, $8 \mu \mathrm{L}$ of plasmid that was less than $6 \mathrm{~kb}$ and had a concentration of $50-150 \mathrm{ng} / \mu \mathrm{L}$ (obtained by DNA mini-prep and determined by Nanodrop), and $5 \mu \mathrm{L}$ of primer that had a concentration of $5 \mu \mathrm{M}$. The reaction mix was sent to Eton Bioscience for DNA sequencing.

Sequence Analysis of LL25X

Once the DNA sequence results were received from Eton Bioscience, the software Geneious was used to analyze the sequence of LL25X.

Bacteria Culture in Aqueous LB media with Ampicillin, followed by DNA Maxi-prep

A selected positive clone was cultured for 8 hours in a culture tube containing $3 \mathrm{ml}$ of LB/Ampicillin media. From the tube, roo $\mu \mathrm{L}$ of the culture was transferred to a flask with $500 \mathrm{ml}$ of LB/Ampicillin and cultured overnight. The culture was transferred into centrifugation tubes the next day. The centrifuge was set at 7,000 rpm for I5 minutes to pellet the cells. The supernatant was discarded, and the pellet was obtained.

The PureLink HiPure Plasmid DNA Purification Kit Maxiprep procedure by Invitrogen was followed to extract DNA from the pellet. The supernatant was removed, and the pellet was air-dried for Io minutes and resuspended in Ioo $\mu \mathrm{L}$ of double distilled water, rather than the recommended $500 \mu \mathrm{L}$ of TE Buffer (TE).

Initiation to Tissue Culture

Human Embryonic Kidney 293 cells (HEK293) of the 293T cell line were used. For storage, cells were trans- ferred into a new T75 flask containing $500 \mathrm{ml}$ of medium consisting of $440 \mathrm{ml}$ of RPMI $+50 \mathrm{ml}$ of IO\% FBS, $5 \mathrm{ml}$ of supplemental glutamine $200 \mathrm{mM} \mathrm{L}$-glu, and $5 \mathrm{ml}$ of Ix Penicillin and Ix Streptomycin.

Transfection of $239 \mathrm{~T}$ Cells

The pCEP4/LL25X DNA that was isolated via maxi-prep was used to transfect 293T cells by following the Lipofectamine 2000 DNA Transfection Reagent Protocol.

One day before transfection, the $293 \mathrm{~T}$ cells were trypsinized and resuspended into a Io $\mathrm{ml} / \mathrm{T} 75$ flask. Using a haemocytometer, the cell number was determined, and trypan blue was added to determine cell viability. The cells were seeded at $6 \times$ IO $^{\wedge} 6$ cells $/ T 75$ flask.

On the day of transfection, the culture media (DMEM consisting of I0\% FBS, Ix PBS (Phosphate Buffer Saline)/ Strep, Ix Glutamine) replaced the old media I hour before transfection. The transfection mixture was prepared using $500 \mu \mathrm{L}$ of Serum-free media (SFM ie. OPTI-MEM) + Io $\mu \mathrm{g}$ of maxi-prep DNA, $500 \mu \mathrm{L}$ of SFM + Io $\mu \mathrm{L}$ of Lipofectamine 2000 reagent, and DNA mix, which was incubated before at room temperature for 20 minutes. The transfection mixture was added to the cell culture and incubated overnight at $37^{\circ} \mathrm{C}, 5 \% \mathrm{CO}_{2}$, and $70 \%$ humidity. Cleavage of SIVmac239gpi4o into monomeric surface subunit SIVmac239gpi2o and ectodomain SIVmac239gp4I occurred once the proteins were expressed in the 293T cells.

One day after transfection, the culture media was replaced with Io $\mathrm{ml}$ of SFM=DMEM (Ix Pen/Strep, Ix Glutamine, and without FBS). Five days after transfection, the culture supernatant was transferred into I5 $\mathrm{ml}$ conical tubes. The tubes were centrifuged at 3,000 rpm for 10 min to pellet the debris in the tube. The supernatant was transferred to new I5 $\mathrm{ml}$ conical tubes.

\section{Protein Purification}

The Purification on Protein A-Agarose Protocol by Roche was followed to purify the protein. The resulting eluate, 
containing the protein, was mixed by vortex and transferred into a dialysis cassette (Io,000 Molecular Weight Cut-Off MWCO). Dialysis was performed overnight in IxPBS at $4{ }^{\circ} \mathrm{C}$ and was slowly stirred.

The next day, a centrifugal filter unit (Amicon Ultracel Io,००० MUCO) was used to concentrate the protein eluate until the remaining buffer was around I00-200 $\mu \mathrm{L}$. The unit was centrifuged at 3,000 rpm for 30 minutes.

Protein/Antibody Characterization by ELISA (EnzymeLinked Immuno-sorbant Assay)

Antigens (SIVmac239gpi40, SIVmac239gpi20, and control BSA) were prepared at I ng $/ \mu \mathrm{L}$ with IxPBS. A plate was divided so that Ioo $\mu \mathrm{L}$ of each diluted antigen was added to each corresponding well. The coated ELISA plate was incubated for I hour at $37^{\circ} \mathrm{C}$. After incubation, the plate was washed once with IxPBS containing $0.5 \%$ Tween 20 . The tray was blocked by adding $500 \mu \mathrm{L}$ of $5 \%$ skim milk in IxPBS. The tray was sealed and incubated for I hour at $37^{\circ} \mathrm{C}$

A Iooox serial dilution of the primary antibody/protein was prepared, beginning with Io $\mu \mathrm{g} / \mu \mathrm{L}$. The dilutions were Io $\mu \mathrm{g} / \mu \mathrm{L}$, I $\mu \mathrm{g} / \mu \mathrm{L}$, and o.I $\mu \mathrm{g} / \mu \mathrm{L}$. The dilutions were prepared using IxPBS/FBS $2 \%$, and $50 \mu \mathrm{L}$ of the antibody/ protein dilution was added to each well. For each antigen, one of each dilution was added. Therefore, each antigen would have three different dilutions. The tray was incubated for I hour at $37^{\circ} \mathrm{C}$. The plate was washed ro times with IxPBS containing $0.5 \%$ Tween 20 and flipped over on a paper towel to dry for I minute. After drying the tray, 50 $\mu \mathrm{L}$ of secondary antibodies, HRP-conjugate anti-human IgG antibodies (I000x dilution in 5\% skim milk), were added to all of the wells. The tray was sealed and incubated for I hour at $37^{\circ} \mathrm{C}$. The plate was washed 5 times with IxPBS containing $0.5 \%$ Tween 20 and flipped over to dry on a paper towel for I minute, and roo $\mu \mathrm{L}$ of TMB solution was added. The plate was incubated for 30 minutes at room temperature. Once blue color was observed, the reaction was stopped with roo $\mu \mathrm{L}$ of TMB stop solution. The absorbances of the wells were read on Wallac (Victor plate reader) at $450 \mathrm{~nm}$.

\section{Protein Charcterization by Coomassie Blue Staining}

A I2 \% agarose gel was prepared. Samples to be loaded into the wells consisted of $5 \mu \mathrm{g}$ of each envelope protein (gpi2o and gpi40) and IxPBS was added to each sample until a total volume of Io $\mu \mathrm{L}$ was achieved. To the ro $\mu \mathrm{L}$ of each sample, Io $\mu \mathrm{L}$ of $2 \mathrm{x}$ Sample Loading Buffer was added for a total volume of $20 \mu \mathrm{L}$. The samples were boiled at $100^{\circ} \mathrm{C}$ for 5 minutes, spun down, and loaded onto the gel. Lane I contained the ladder, Lane 2 contained the Env glycoprotein, gpi2o, and Lane 3 contained the Env glycoprotein, gpi40. After the gel was run, the gel was stained with Coomassie Blue, and the protein bands were observed.

Protein/Antibody Characterization by Western Blotting A I2 \% agarose gel was prepared. Samples to be loaded into the wells consisted of $5 \mu \mathrm{g}$ of each protein/antibody (SU24, $\mathrm{SU}_{343}$, and LL25X) and IxPBS was added to each sample until a total volume of ro $\mu \mathrm{L}$ was achieved. To the ro $\mu \mathrm{L}$ of each sample, Io $\mu \mathrm{L}$ of $2 \mathrm{x}$ Sample Loading Buffer was added for a total volume of $20 \mu \mathrm{L}$. The samples were boiled at $100^{\circ} \mathrm{C}$ for 5 minutes, spun down, and loaded onto the gel. Lane I contained the ladder, Lane 2 contained SU24-Fc, Lane 3 contained SU343-Fc, and Lane 4 contained LL25XFc. After the gel was run, the proteins in the gel were transferred to a nitrocellulose membrane. The membrane was blocked by using $5 \%$ skim milk to prevent nonspecific binding and was treated with the primary antibody, AntiIgG-HRP. The membrane was left for I hour in $5 \%$ skim milk that was prepared with IxPBS. The gel was washed 3 times with IxPBS for Io minutes each. This membrane, Blotting Gel I, consisted of SU24, SU343, and LL25X and used anti-human IgG-HRP as the primary antibody.

Three I2\% agarose gels were prepared. Samples to be loaded into the wells consisted of $5 \mu \mathrm{g}$ of each protein/ antibody (SIVmac239gpi2o and SIVmac239gpi40) and Io $\mu \mathrm{L}$ of $2 \mathrm{x}$ Sample Loading Buffer, and IxPBS was added to each sample until a total volume of Io $\mu \mathrm{L}$ was achieved. The samples were boiled at $100^{\circ} \mathrm{C}$ for 5 minutes, spun down, and loaded onto the gel. Lane I contained the ladder, Lane 2 contained the Env glycoprotein, gpi2o, and Lane 3 contained the Env glycoprotein, gpi4o. After the gel was run, the proteins in the gel were transferred to a nitrocellulose membrane.

For the first gel, Blotting Gel 2, the membrane was blocked by using $5 \%$ skim milk to prevent nonspecific binding and was treated with the primary antibody, SU24. The membrane was left for I hour in $5 \%$ skim milk that was prepared with IxPBS. The gel was washed 3 times with IXPBS for Io minutes each. Anti-human IgG-HRP was added as the secondary antibody. The gel was washed 3 times with IxPBS for Io minutes each. The chemiluminescence reagent was added to the gel. The gel was observed under UV light, and pictures were taken 
using the Chemiluminescence Dock. The first gel contained SIVmac239gpizo and SIVmac239gpi40, used $\mathrm{SU}_{24}$ as the primary antibody, and used anti-human IgGHRP as the secondary antibody.

For the second gel, Blotting Gel 2, the membrane was blocked by using 5\% skim milk to prevent nonspecific binding and was treated with the primary antibody, $\mathrm{SU}_{343}$. The membrane was left for I hour in 5\% skim milk that was prepared with IxPBS. The gel was washed 3 times with IxPBS for Io minutes each. Anti-human IgG-HRP was added as the secondary antibody. The gel was washed 3 times with IxPBS for Io minutes each. The chemiluminescence reagent was added to the gel. The gel was observed under UV light, and pictures were taken using the Chemiluminescence Dock. The second gel contained SIVmac239gpi2o and SIVmac239gpi40, used SU343 as the primary antibody, and used anti-human IgG-HRP as the secondary antibody.

For the third gel, Blotting Gel 2, the membrane was blocked by using $5 \%$ skim milk to prevent nonspecific binding and was treated with the primary antibody, LL25X. The membrane was left for I hour in 5\% skim milk that was prepared with IxPBS. The gel was washed 3 times with IxPBS for Io minutes each. Anti-human IgG-HRP was added as the secondary antibody. The gel was washed 3 times with IxPBS for Io minutes each. The chemiluminescence reagent was added to the gel. The gel was observed under UV light, and pictures were taken using the Chemiluminescence Dock. The third gel contained SIVmac239gpi2o and SIVmac239gpi40, used LL25X as the primary antibody, and used anti-human IgG-HRP as the secondary antibody.

\section{RESULTS}

After PCR, the bright band was observed, as shown in Figure Ia. The location of the band is approximately at Io92 $\mathrm{bp}$, which is the size of the LL25X fragment. This indicates that the LL25X fragment was successfully amplified. The PCR products, corresponding to a codon-optimized version of LL25X plus the hinge region $(\mathrm{H})$ of a human IgGI, were extracted from the gel. The amplified LL25X fragments were double digested with $\mathrm{KpnI}$ and SapI, and the double digest products were run on $\mathrm{I} \%$ agarose gel. The resulting insert vector, an $\mathrm{scFv}$, was extracted from the gel. The mammalian expression vector $\mathrm{pCEP}_{4}$ was also double digested with KpnI and SapI, and the double digest prod-

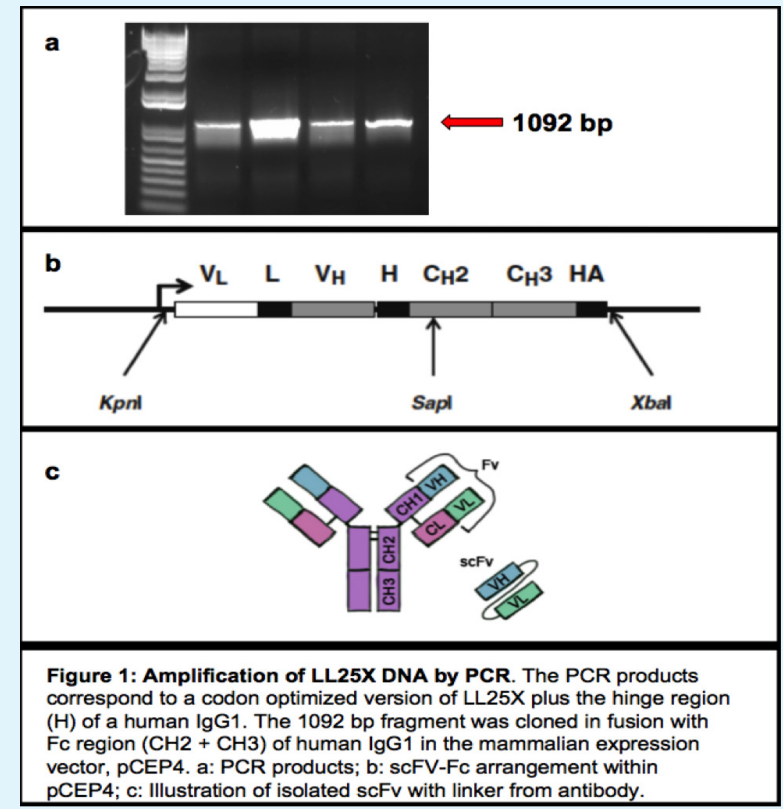

ucts were run on I\% agarose gel. The resulting backbone vector was extracted from the gel.

Using complementary "sticky ends," which resulted from the double digest, the insert vector, LL25X, was effectively ligated into the backbone vector, pCEP4. TOPıOF' E. coli were transformed with the ligation product; the Io92 bp fragment was cloned in fusion with the $\mathrm{Fc}$ region $\left(\mathrm{CH}_{2}+\right.$ $\mathrm{CH}_{3}$ ) of human IgGr in the mammalian expression vector pCEP4. These cells, containing the ligation product, were grown on LB agar plates containing Ampicillin, as shown in Figure 2b. A negative background control with E. coli

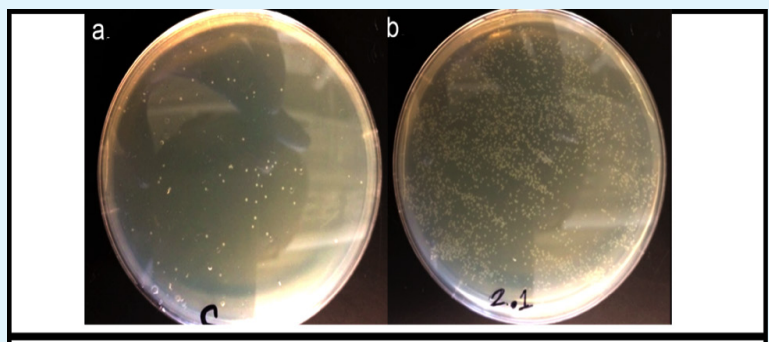

Figure 2: Identification of Positive Clones on Selective Media LL25X was ligated into PCEP4, and TOP10F' E. coli were transformed with the ligation product. Single colonies were selected and inoculated into culture tubes containing $3 \mathrm{~mL}$ LB media supplemented with $50 \mu \mathrm{g} / \mathrm{ml}$ of Ampicillin. a: negative control with the digested vector only $b$ : vector + insert ligation product. The greater amount of colonies obtained with "vector + insert" suggested a successful ligation reaction. 
containing mammalian expression vector pCEP4-Fc-HA, digested and ligated without the LL25X insert vector, was also grown on LB agar plates containing Ampicillin, as shown in Figure $2 \mathrm{a}$.

Theoretically, there should not be any growth on the negative control. The vector, digested and ligated without LL25X, would not be able to provide antibiotic resistance because the replication machinery of the bacteria would be affected, preventing the replication of the plasmid. Since the plasmid is not replicated, the Ampicillin resistance gene cannot be expressed. However, the growth of a few colonies is clearly visible. This incidence may be due to some of the pCEP4 not being completely digested, resulting in a functional Ampicillin resistance gene. There is an abundance of colonies on the plate with the bacteria that contain the ligation product. The ligation of LL25X to the backbone vector pCEP 4 allows the cell to replicate, resulting in the expression of the Ampicillin resistance gene. The greater amount of colonies present on the plate with the bacteria containing the ligation product compared to the plate with the bacteria containing $\mathrm{PCEP}_{4}$, digested and ligated without LL25X, suggests a successful ligation reaction. A colony, corresponding to the bacteria transformed with the $\mathrm{pCEP} 4 / \mathrm{LL} 25 \mathrm{X}$ ligation product, was selected, and the pCEP4/LL25X DNA from the colony was extracted via DNA mini-prep.

The pCEP4/LL25X DNA and the pCEP4-Fc-HA DNA, used as a control, were double digested with KpnI-HF/ SapI and KpnI/BamHI-HF. The products of the double digests were run on $\mathrm{I} \%$ agarose gel. The $\mathrm{pCEP} 4 / \mathrm{LL} 25 \mathrm{X}$ DNA double digested with KpnI-HF and SapI produced a band at approximately Io92 bp, and the pCEP4-Fc-HA DNA double digested with KpnI-HF and SapI also produced a band at approximately I092 bp. The double digested DNA fragments were similar in size; therefore, it could not be verified that the ligation product contained the LL25X DNA based on this result alone. When double digested with KpnI and BamHI-HF, pCEP4/LL25X DNA and pCEP4-Fc-HA DNA resulted in bands with different sizes. This is due to the BamHI restriction site residing in different locations between the two vectors. The pCEP4/LL25X contains a BamHI restriction site that appears before SapI, and the pCEP4-Fc-HA DNA contains a BamHI restriction site that appears after SapI; therefore, the double digested pCEP4/LL25X DNA will result in a smaller fragment than the fragment produced by the double digested pCEP4-FcHA DNA. This result verified that the ligation product contained the LL25X DNA.

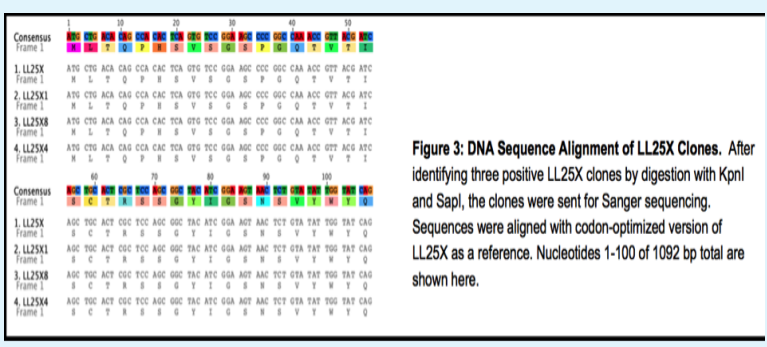

After identifying three positive LL25X clones via double digestion, the clones were sent to Eton Bioscience for Sanger sequencing. Once the DNA sequence results were received, the software Geneious was used to analyze the sequence of LL25X. The sequence analysis confirmed that the correct LL25X sequence had been cloned into the mammalian expression vector $\mathrm{pCEP} 4$. The sequences of all three LL25X clones were aligned identically to the original codon-optimized version of the LL25X sequence, as shown in Figure 3.

A positive LL25X clone was also selected to be cultured in a tube containing $3 \mathrm{ml}$ of LB/Ampicillin media, and the resulting $\mathrm{pCPE}_{4} / \mathrm{LL}_{25} \mathrm{X}$ DNA from the bacteria was extracted via DNA maxi-prep. The extracted $\mathrm{pCEP}_{4} / \mathrm{LL} 25 \mathrm{X}$ DNA was used to transfect $293 \mathrm{~T}$ cells. Cleavage of SIVmac239gpi4o into monomeric surface subunit SIVmac239gpi20 and ectodomain SIVmac239gp4I occurred once the proteins were expressed in the $293 \mathrm{~T}$ cells. Five days after the transfection, the culture supernatant was centrifuged to remove the cell debris, and the supernatant was transferred to new tubes. The proteins in the supernatant

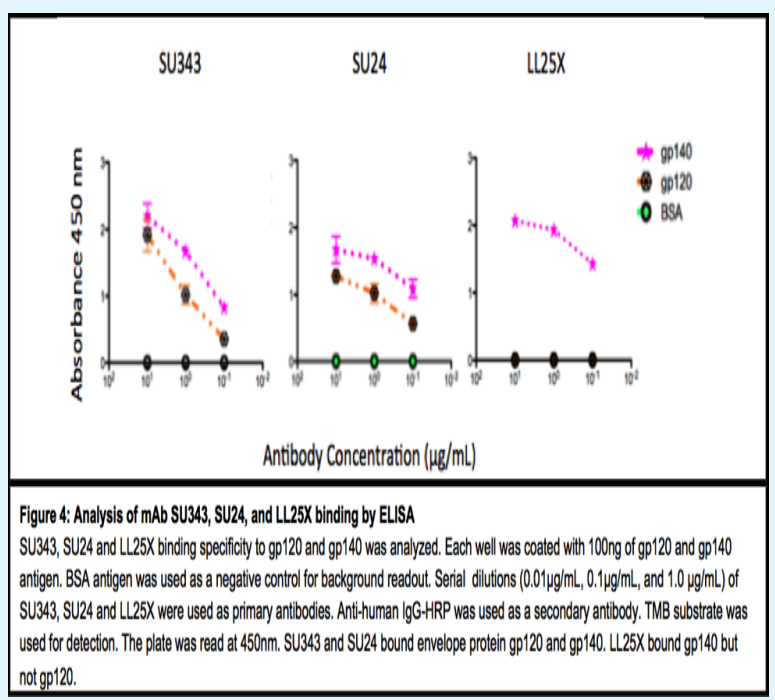




\section{"ELISA determined that the protein, LL25X-FC, binds to Env glycoprotein SIVmac239gp140 and not monomeric surface subunit SIVmac239gp120."}

were isolated via Protein A-Agarose beads and dialysis, and ELISA was performed, as shown in Figure 4.

The binding specificity of antibodies, $\mathrm{SU}_{24}, \mathrm{SU}_{343}$, and LL25X, against antigens, SIVmac239gpi40, SIVmac239gpi2o, and BSA (Bovine Serum Albumin - used as a control), was analyzed. SU24, SU343, and LL25X were used as primary antibodies, and anti-human IgG-HRP was used as a secondary antibody. TMB solution was used for detection, and the plate was read at $450 \mathrm{~nm}$. SU24, $\mathrm{SU}_{343}$, and LL25X did not bind to BSA, which was expected. SU24 and $\mathrm{SU}_{343}$ bound to the envelope proteins gpi40 and gpi20; however, LL25X bound to gpi40 but not gpi2o. ELISA determines the binding specificities of antibodies to antigens; however, ELISA does not reveal the specific location on the antigen to which the antibody binds. Further tests were required to determine the location of where the binding of LL25X occurred on gpi40.

Coomassie Blue Staining was performed to determine the presence and quantity of proteins since the dyes bind directly to the proteins, as shown in Figure $5 \mathrm{~b}$. The Coomassie gel displayed equal loading amounts of both gpi4o

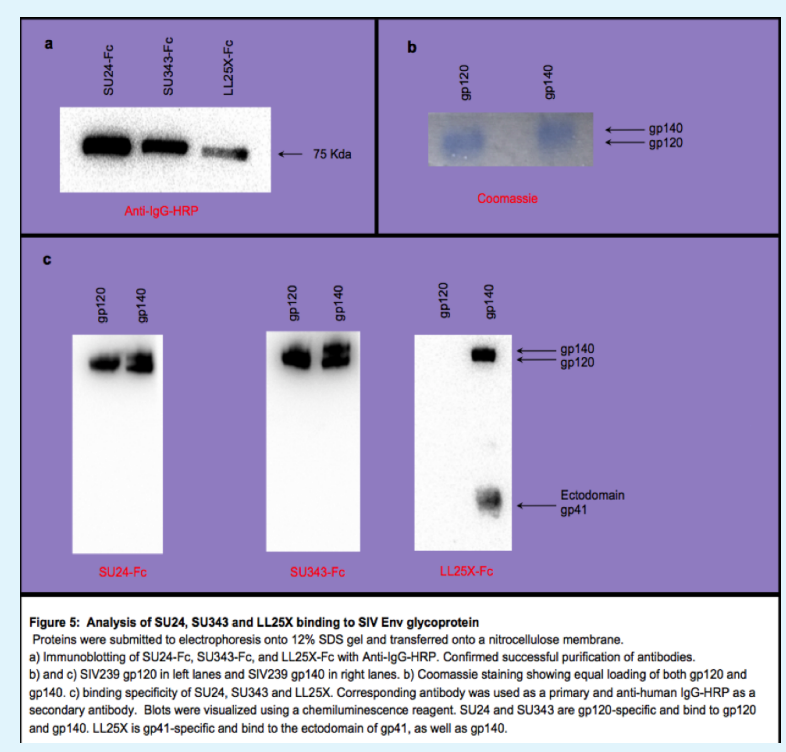

and gpi2o. Western blotting was performed to determine the locations on antigens where the binding of antibodies occurred, such as the location where the binding of LL25X occurred on gpi40. Figure 5a displays the immunoblotting of $\mathrm{SU}_{24}$, SU343, and LL25X with Anti-IgG-HRP. The gel confirmed successful purification of antibodies since AntiIgG-HRP was able to bind to all 3 antibodies.

Figure $5 \mathrm{~b}$ displays the binding specificity of $\mathrm{SU}_{24}, \mathrm{SU}_{343}$, and LL25X, which were used as primary antibodies, and anti-human IgG-HRP was used as a secondary antibody. The results of the Western blots supports the data received from ELISA. SU24 and SU343 were revealed to be gpi2ospecific, and thus, bound to both gpi2o and gpi4o, as illustrated by the dark bands. LL25X was revealed to be gp4I-specific, and thus, bound to both gp4I and gpi40, as illustrated by the dark bands. A band is present at the gpi4o location because not all of the gpi4o was cleaved. LL25X binds to ectodomain gp4I that that remained a part of Env glycoprotein gpi4o. The lack of a band at the gpı2o location indicates that LL25X did not bind to the monomeric surface subunit gpi2o of the Env glycoprotein gpi40. The band at the gp4I location indicates that LL25X binds to the ectodomain gp4I of Env glycoprotein gpi40.

\section{CONCLUSION}

The LL25X DNA fragment was successfully cloned into the mammalian expression vector $\mathrm{pCEP}_{4}$ by digesting the LL25X PCR products and the cloning vector pCEP4 with KpnI and SapI, ligating the resulting LL25X insert vector and the resulting $\mathrm{pCEP}_{4}$ backbone vector, and transforming E. coli TOPıF' cells with the ligated product. The LL25X scFv fragment that was inserted and fused to the Fc region $\left(\mathrm{CH}_{2}+\mathrm{CH}_{3}\right)$ of human IgGI in the mammalian expression vector pCEP4 was confirmed and verified by DNA sequence analysis. ELISA determined that the protein, LL25X-Fc, binds to Env glycoprotein SIVmac239gpi40 and not monomeric surface subunit SIVmac239gpi20. Monoclonal SIVmac239 antibodies SU24 and $\mathrm{SU}_{343}$ were also revealed to bind to monomeric surface subunit SIVmac239gpizo and Env glycoprotein SIVmac- 
